\title{
Acute bloody diarrhea with right sided colitis
}

\author{
DESMOND J. LEDDIN, MB, MRCP(I), FRCP(C), \\ JAMES A. BARROWMAN, MB, FRCP (LOND), FRCP (C), PHD
}

\begin{abstract}
A 50-year-old woman presented with bloody diarrhea and radiological evidence of right sided colitis. Enterohemorrhagic Escherichia coli was isolated from the stool. The illness subsided spontaneously but was complicated by the development of hypoproteinemia and ascites. This disease presents a variable clinical picture but apparent 'ischemic colitis' in younger patients is especially suggestive of infection with E coli 0157:H7. Can J Gastroenterol 1988; 2(1):37-40
\end{abstract}

Key Words: Colitis, Escherichia coli 0157:H7
A 50-YEAR-OLD WOMAN WAS SEEN in the emergency department with abdominal pain and bloody diarthea.

Six days earlier she had awoken with severe right lower quadrant abdominal cramps. Several hours later watery diarrhea developed with bowel movements every 1 to $2 \mathrm{~h}$. Within $24 \mathrm{~h}$ the stools became grossly bloody. At this time she became nauseated and vomited several times.

Stool specimens for culture had been sent by her family doctor shortly after the illness began. These were reported as negative for pathogens.

Three days prior to the onset of symptoms, two family members had been acutely ill with watery diarrhea. Their illnesses resolved spontaneously. Stool cultures were not obtained.

There was no history of recent travel outside Canada. The patient had not had any animal contact, had not eaten any unusual foods and had not received antibiotics in several years.

Her previous history was unremarkable. Specifically, there was no history
Faculty of Medicine, Memorial University of Newfoundland, St John's, Newfoundland AlB 3 V6

Received for publication November 1, 1987. Accepted December 1, 1987 of liver disease or excessive alcohol intake. She was not receiving any medications.

On examination she appeared ill and was mildly dehydrated. Temperature was $36.8^{\circ} \mathrm{C}$, pulse $115 / \mathrm{min}$ and regular and blood pressure 170/100 $\mathrm{mmHg}$. Examination of the head and neck revealed no abnormalities. The chest was clear and heart sounds normal. Abdominal examination revealed no areas of tenderness, liver and spleen were not enlarged. Bowel sounds were normal but an epigastric bruit was heard. There were no stigmata of liver disease and foot pulses were normal.

\section{LABORATORY INVESTIGATIONS}

Hemoglobin was $183 \mathrm{~g} / \mathrm{L}$, hematocrit 0.53 and white cell count $20,500 / \mathrm{mm}^{3}$ with $63 \%$ neutrophils, $28 \%$ stabs, $7 \%$ lymphocytes and $2 \%$ monocytes. Serum sodium was 130 $\mathrm{mmol} / \mathrm{L}$ (normal, 135 to $145 \mathrm{mmol} / \mathrm{L}$ ) and potassium $3.0 \mathrm{mmol} / \mathrm{L}$ ( 3.5 to 5.0 
$\mathrm{mmol} / \mathrm{L})$. Serum chloride was 93 $\mathrm{mmol} / \mathrm{L}(98$ to $110 \mathrm{mmol} / \mathrm{L}$ ) and $\mathrm{bi}$ carbonate $25.2 \mathrm{mmol} / \mathrm{L}$ (22 to 32 $\mathrm{mmol} / \mathrm{L})$. Blood urea was $4.8 \mathrm{mmol} / \mathrm{L}$ (3.0 to $6.5 \mathrm{mmol} / \mathrm{L}$ ) and creatinine 72 $\mu \mathrm{mol} / \mathrm{L}$ (40 to $130 \mu \mathrm{mol} / \mathrm{L}$ ). Serum bilirubin was $4.8 \mu \mathrm{mol} / \mathrm{L}$ (less than 18 $\mu \mathrm{mol} / \mathrm{L}$ ), serum aspartate aminotransferase (AST) was $17 \mathrm{iu} / \mathrm{L}$ (less than 38 $\mathrm{iu} / \mathrm{L}$ ), alanine aminotransferase (ALT) was $17 \mathrm{iu} / \mathrm{L}$ (less than $38 \mathrm{iu} / \mathrm{L}$ ) and alkaline phosphatase was $74 \mathrm{iu} / \mathrm{L}$ (40 to $120 \mathrm{iu} / \mathrm{L})$. Serum albumin was $27 \mathrm{~g} / \mathrm{L}$ ( 35 to $50 \mathrm{~g} / \mathrm{L}$ ). Urinalysis showed a trace of protein and no red cells or casts. Repeat stool cultures showed no growth of pathogens.

Sigmoidoscopy revealed edematous colonic mucosa without ulceration.

Following admission the patient appeared to deteriorate. She had frequent bloody bowel movements and developed abdominal distension. Because of the possibility of ischemic colitis, a barium enema was performed (Figure 1, left panel) and this showed marked irregularity of the ascending and proximal transverse colon with thumb printing. This was consistent with the diagnosis of ischemic disease. The rest of the colon and the terminal ileum were within normal limits.

Six days after admission Escherichia coli $0157: \mathrm{H} 7$ positive for Verotoxin was isolated from the patient's stool.

The patient was treated with intravenous fluids and appropriate corrections were made to her electrolytes. The diarrhea settled spontaneously. On the 10th day of her illness the white cell count was normal. By the 12 th day her bowel frequency decreased to two bloodless formed stools per day. At this point she was noted clinically to have ascites with a fluid thrill.

At this time serum albumin was 31 $\mathrm{g} / \mathrm{L}$ (normal 35 to $50 \mathrm{~g} / \mathrm{L}$ ) and urinalysis was negative for protein. Serum bilirubin was $5 \mu \mathrm{mol} / \mathrm{L}$, AST was 26 $\mathrm{iu} / \mathrm{L}$ and ALT was $36 \mathrm{iu} / \mathrm{L}$. The prothrombin time was $13 \mathrm{~s}$ (12 to $15 \mathrm{~s}$ ) and partial thromboplastin time was $28 \mathrm{~s}(25$ to $37 \mathrm{~s}$ ). The ascites quickly resolved and because the patient was clinically well further investigations were not performed.

She was discharged on the 16th day

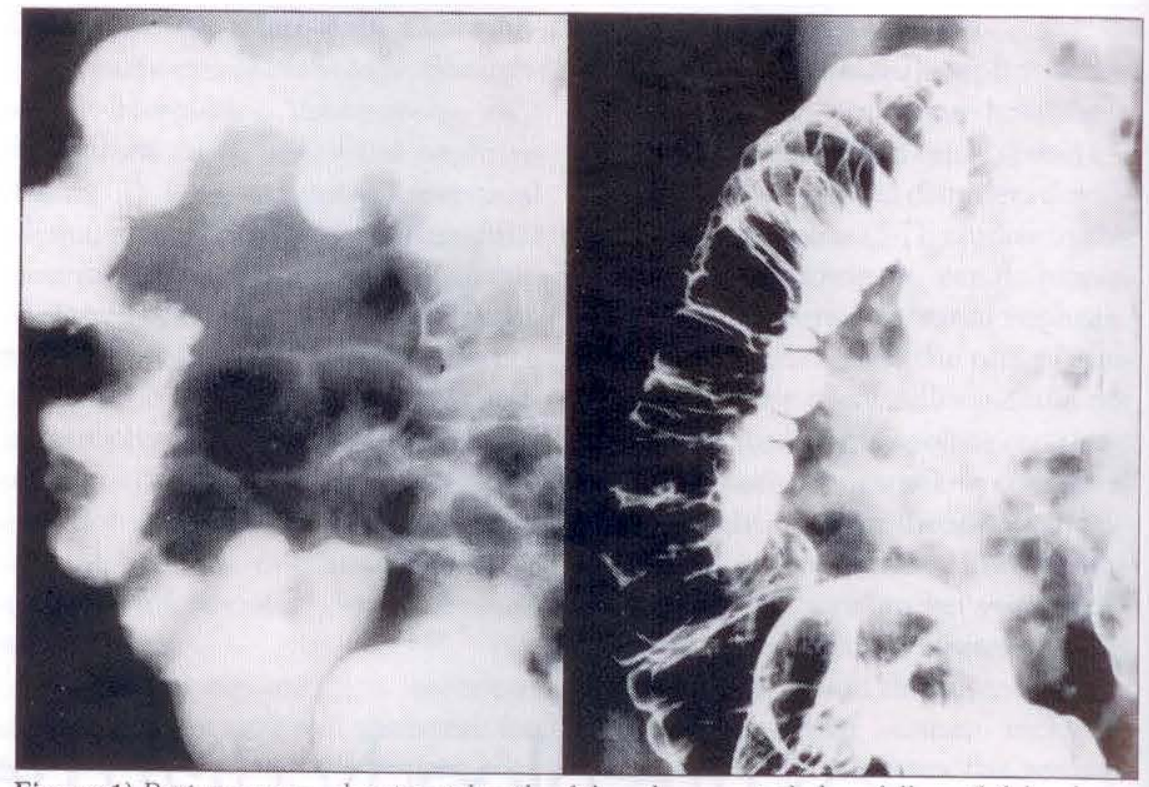

Figure 1) Barium enema, showing right side of the colon, on ninth day of illness (left hand panel) and eight weeks later (right hand panel)

of her illness at which time her bowel movements had returned to normal.

Eight weeks later she was asymptomatic without ascites. Serum albumin was $49 \mathrm{~g} / \mathrm{L}$. Repeat barium enema was entirely within normal limits (Figure 1, right panel).

\section{DISCUSSION}

A 50-year-old woman presented with bloody diarrhea in the absence of fever or systemic illness. The acute onset of illness with abdominal pain, watery diarrhea and later bloody diarrhea was suggestive of an infectious etiology. Two family members had already been ill. Stool cultures, however, showed no growth of the common enteric pathogens. Colonic ischemia was considered and the finding of an epigastric bruit supported this diagnosis.

Sigmoidoscopic examination showed edematous mucosa but no specific abnormalities. Barium enema showed changes in the right colon compatible with ischemic disease.

Until relatively recently the diagnosis would not have been elucidated further. The isolation of enterohemorrhagic $E$ coli from the repeat stool cultures and the recognition that this organism may cause right sided colitis enabled the correct diagnosis to be made.
The recognition of $E$ coli as pathogenic is attributable to Bray and Beavan (1). In the 1940s, in England, they recognized that only a fraction of childhood diarrheas were explicable on the basis of known pathogens. They postulated that $E$ coli might, in some circumstances, be capable of producing diarrhea. Rabbit antiserum was prepared to $E$ coli cultured from the stool of a child with diarrhea. Using the antiserum they were able to demonstrate the presence of the same organism in subsequent outbreaks of diarrhea as compared to a control population without the illness. Thus they provided evidence of the pathogenicity of certain $E$ coli strains.

Since that time there has been an enormous increase in our knowledge of pathogenic $E$ coli. The organism may be classified on the basis of the $\mathrm{O}$ (lipopolysaccharide), $\mathrm{H}$ (flagellar) and $\mathrm{K}$ (polysaccharide) antigens. Subsequent assignment to enteropathogenic, entertoxigenic, enteroinvasive, enteroadherent or enterohemorrhagic groups is clinically of little benefit because pathogenesis is not yet clear and because the organism does not always produce disease appropriate to its classification. The affected family members in the present case likely had enterohemorrhagic $E$ coli but yet had a 
watery diarrhea without gross blood. The ability of enterohemorrhagic E coli to produce watery diarrhea has been reported previously (2).

The 0157:H7 strain of $E$ coli was first recognized in Irish piglets in 1970 (3) as a cause of enteritis. Since then, sporadic and clustered cases have been reported. Outbreaks have been described in homes for the aged (4) and in a day care centre (5).

The disease is characterized by an incubation period of three to nine days with a median of four days (4). The organism may be ingested in contaminated food. Hamburger from a restaurant chain was responsible for an outbreak in the United States (6). Infection via fecal oral contamination and via fomites likely occurs (5). Typically the infection begins with crampy abdominal pain followed by watery diarrhea which may become grossly bloody. There may be nausea and vomiting but fever is uncommon. Some patients have symptoms suggestive of an upper respiratory infection (6).

Laboratory evidence of inflammation may be absent. The erythrocyte sedimentation rate and white cell count may be normal or only minimally elevated (6).

Sigmoidoscopic examination may be normal or show abnormalities ranging from edema to frank ulceration (2). Colonoscopically the disease may be most marked in the proximal colon and edema, inflammation and hemorrhage have been reported (2). Barium enema may be normal or show, as in this case, changes suggestive of submucosal edema $(2,6)$.

The disease appears to show a predilection for the right colon and may mimic ischemic disease. It seems likely in milder cases, or in cases where the patient is seen some time after the onset of the illness, that no significant lesion may be seen endoscopically or radiologically. The disease appears to resolve without residual colonic scarring.

The illness is usually self-limited with a mean duration of eight days (2) but in the elderly and very young it may be fatal. A mortality rate of $36 \%$ was reported for an outbreak in Lon- don, Ontario in 1985 (4). There is an association with hemolytic uremic syndrome a complication which carries a high mortality $(2,5,7)$.

The organism may be found in the stools for up to 14 days (8) but is more likely to be detected if stools are collected within the first six days of illness (9).

Treatment consists of fluid and electrolyte replacement. Trimethoprimsulfamethoxazole or ampicillin may be effective in shortening the duration and severity of illness (10). There are, however, no controlled trials of antibiotic efficacy. In the retrospective data presented by Remis and colleagues (2) the mean duration of illness in patients receiving antibiotics was 7.5 days as compared to 8.5 days in untreated patients. Of particular importance would be a trial designed to show whether antimicrobial therapy prevented the development of disease and hemolytic uremic syndrome in contacts.

The organism produces a toxin identical to that of Shigella dysenteriae type 1 (11). This toxin, designated Verotoxin 1, is cytotoxic for HeLa and Vero cells (a cell line derived from monkey kidney cells). A second cytotoxin, Verotoxin 2, not neutralized by antibody to the Shiga toxin may also be found. Some strains produce fimbriae which may be an important factor in determining virulence (12).

Verotoxin has been shown to cause platelet aggregation (13) and this may be important in the pathogenesis of the hemolytic uremic syndrome. $E$ coli $0157: \mathrm{H} 7$ is not the only enteric pathogen associated with hemolytic uremic syndrome. This association has also been reported for Salmonella, Shigella and Campylobacter jejuni.

In the present case the disease followed a relatively benign course. There was no evidence of hemolysis and renal function remained normal. The disease subsided with supportive therapy.

The case presented here is unusual as ascites has not previously been reported as a complication of the illness. The serum albumin was low possibly secondary to protein loss from the inflamed bowel. The low serum oncotic pressure due to hypoalbuminemia no doubt contributed to the ascites but does not seem sufficent to explain it. There was no clinical or laboratory evidence of hepatic or pancreatic disease and no evidence of peritonitis.

When seen in follow-up eight weeks after the onset of the illness the patient was well with a normal serum albumin and no evidence of ascites. Repeat barium enema showed resolution of the colonic abnormalities.

E coli 0157:H7 presents to the gastroenterologist in a variety of ways; as watery diarrhea, bloody diarrhea, colonic bleeding with no apparent cause or as apparent ischemic colitis. The reports of right sided 'ischemic colitis' in young adults (14) reported in the literature prior to recognition of this organism may be descriptions of enterohemorrhagic $E$ coli colitis.

Microbiological laboratories should screen for this organism in all cases of bloody diarrhea when no other pathogen is found. Initial screening is based on the absent or slow fermentation of sorbitol by this strain of $E$ coli. Over $90 \%$ of other strains of E coli ferment sorbitol. If a nonfermenting strain is found it can be serotyped to determine if it is enterohemorrhagic E coli.

The gastroenterologist should consider $E$ coli $0157: H 7$ as a cause of infectious or apparent 'ischemic' colitis when cultures are negative for the common pathogens. This is especially important if barium enema or colonoscopy shows disease predominantly affecting the proximal colon.
$\mathrm{U}$ NE FEMME DE 50 ANS S'EST PRESENTÉE AVEC UNE DIARRHÉE SANGLAUTE et, à l'examen baryté, une colite du côté droit. Les coprocultures ont revélé la présence d'une souche de $E$ coli enterohemorrhagique. Il y eu une amélioration de la maladie cependant elle fut compliquée d'hypoproteinémie et d'ascite. La présentation clinique de cette maladie est variable mais chez les jeunes la découverte d'une 'colite ischémique' suggère fortment une infection causée par $E$ coli $0157: \mathrm{H7}$. 


\section{REFERENCES}

1. Bray J, Beavan TED. Slide agglutination of Bacterium coli var. neapolitanum from summer diarrhea. J Pathol 1948; 60: 395-401.

2.Remis RS, McDonald KM, Riley LW, et al. Sporadic cases of hemorrhagic colitis associated with Escherichia coli 0157:H7. Ann Intern Med 1984; 101: 624-6.

3. Furowicz AJ, Orskov F. Two new Escherichia coli $\mathrm{O}$ antigens, 0150 and 0157 , and one new $\mathrm{K}$ antigen, $\mathrm{K} 92$, in strains isolated from veterinary dis. eases. Acta Pathol Microbiol Scand (B) 1972; 80: 441-4.

4.Pudden D, Tuttle N, Korn D, et al. Hemorrhagic colitis in a nursing home in Ontario. Can Med Assoc J 1986; 134: 50 .

*5.Spika JS, Parsons JE, Nordenberg D, Wells JG, Gunn RA, Blake PA.

Hemolytic uremic syndrome and diarrhea associated with Escherichia coli
0157:H7 in a day care center. J Pediatr 1986; 109: 287-91.

*6. Riley LW, Remis RS, Helgerson SD, et al. Hemorrhagic colitis associated with a rare Escherichia coli serotype. $\mathrm{N}$ Engl J Med 1983; 308: 681-5.

7. Karmali MA, Petric M, Lim C, Fleming PC. Escherichia coli cytotoxin, haemolytic uremic syndrome, and haemorrhagic colitis. Lancet 1983; ii: 1299-1300.

8. Wells JG, Davis BR, Wachsmuth IK, et al. Laboratory investigation of hemorrhagic colitis outbreaks associated with a rare Escherichia coli serotype. J Clin Microbiol 1983; 18: 512-20.

9.Pai CH, Gordon R, Sims HV, Bryan LE. Sporadic cases of hemorrhagic colitis associated with Escherichia coli 0157:H7. Ann Intern Med 1984; 101: 738-42.

10. Levine MM. Antimicrobial therapy for infectious diarrhea. Rev Inf Dis
1986; (Suppl 2): S207-14.

11. O'Brien AD, Thompson MR, Canty JR, Formal SB. Production of a Shigella dysenteriae - like toxin by pathogenic Escherichia coli. Annual meeting of American Society of Microbiology 1977; No. B103.

*12.Levine MM. Escherichia coli that cause diarrhea: Enterotoxigenic, enteropathogenic, enteroinvasive, enterohemorrhagic, and enteroadherent. J Inf Dis 1987; 155: 377-89.

13. Rose PE, Armour JA, Williams CE, Hill FGH. Verotoxin and neuraminidase induced platelet aggregating activity in plasma: their possible role in the pathogenesis of the haemolytic uraemic syndrome. J Clin Pathol 1985; 38: 438-41.

14. Clark AW, Lloyd-Mostyn RH, Sadler MdeC. "Ischaemic" colitis in young adults. Br Med J 1972; 4: 70-2.

* Key reference 


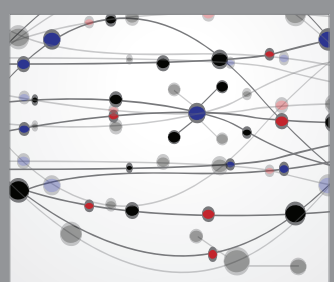

The Scientific World Journal
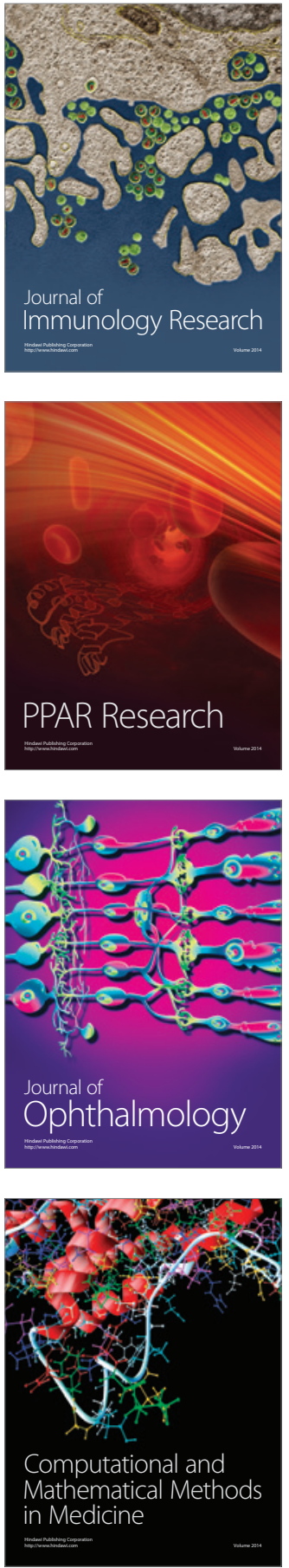

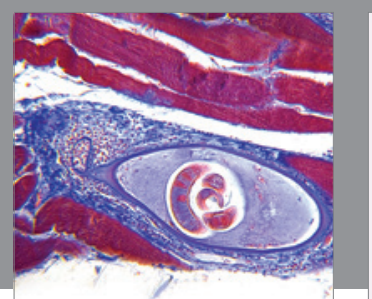

Gastroenterology Research and Practice

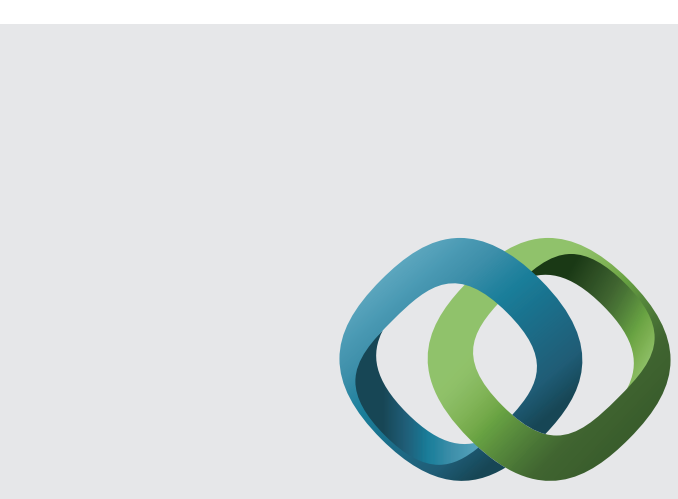

\section{Hindawi}

Submit your manuscripts at

http://www.hindawi.com
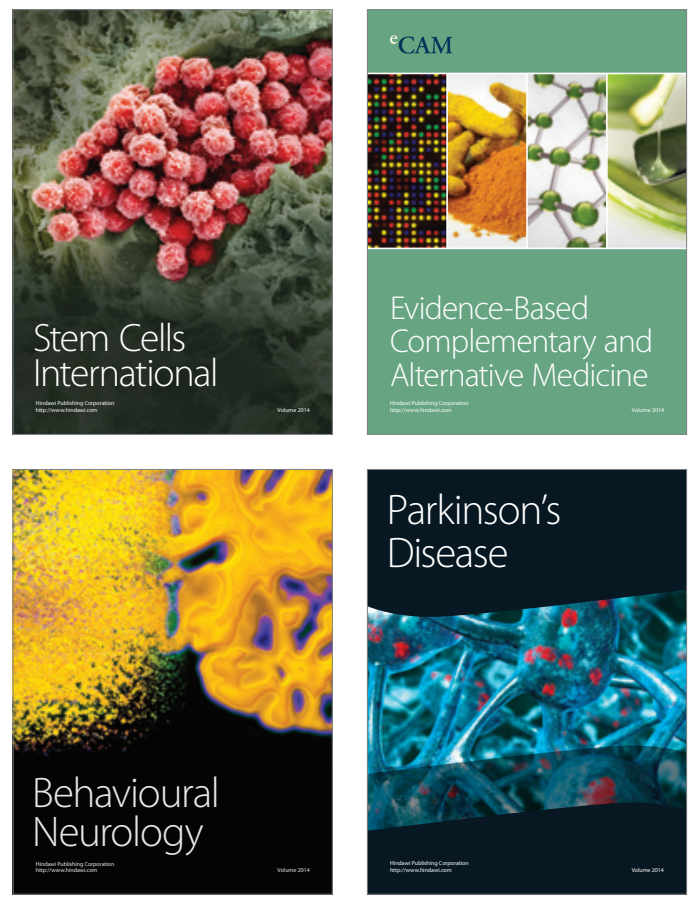
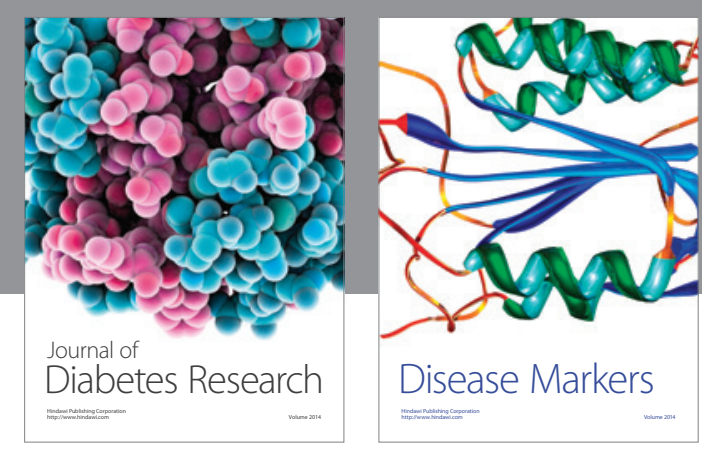

Disease Markers
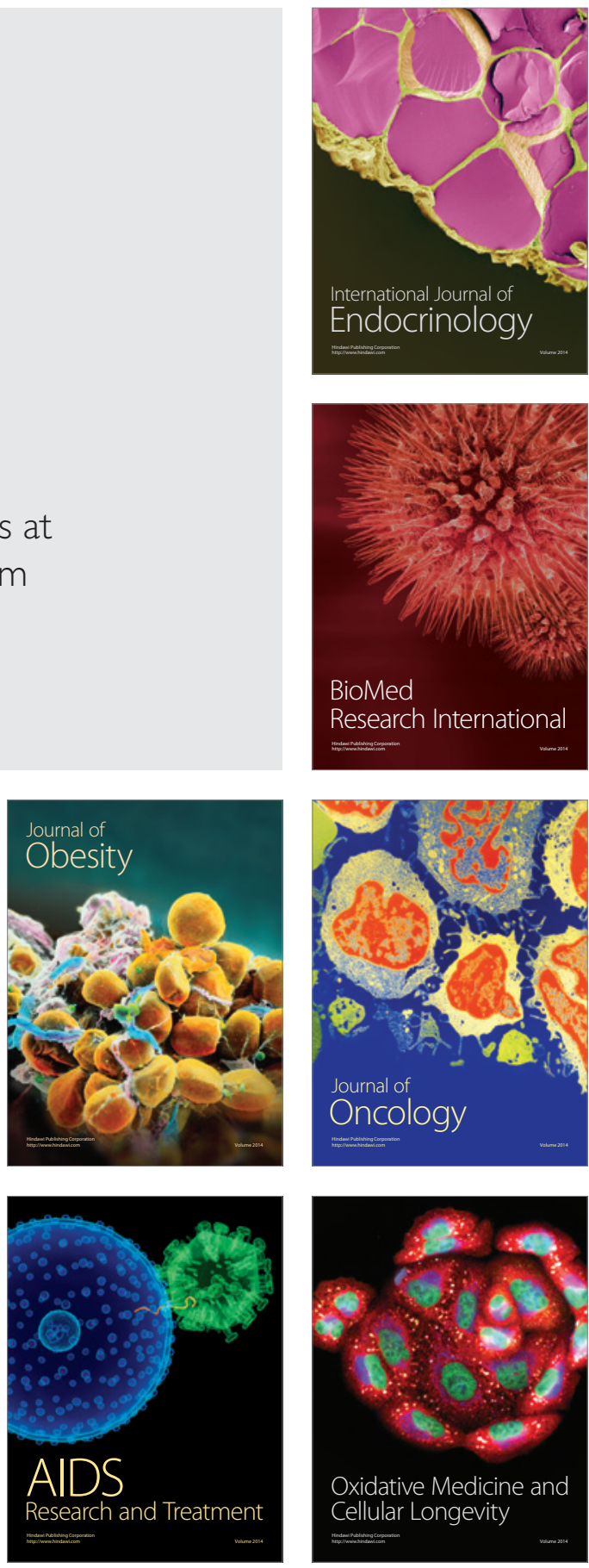